\title{
Cena ao vivo contemporânea: rede de fricções entre o ator performático $e$ fruidor coautor
}

Rita Gusmão ${ }^{1}$

(UFMG - Escola de Belas Artes)

\section{Resumo}

Reflexão sobre os agentes considerados próprios à fruição, como o gosto e o espectador, buscando perceber seus papéis na pós-modernidade e relacionando-os à necessidade de fricção que a arte contemporânea sugere; o objetivo é enxergar como a cena ao vivo contemporânea tem se constituído diante das demandas pós-modernas, seja do ponto de vista do ator e suas transformações, seja do ponto de vista do estabelecimento de categorias novas de relação e de percepção da arte.

Palavras-chave: Cena. Coautoria. Fricção.

\section{Abstract}

Reflection on the agents found fit to fruition, as the taste and the Viewer, seeking to understand their roles in Postmodernity and linking them to the need of friction that suggests contemporary art; the goal is to see how the live contemporary scene has been constituted under the postmodern demands, whether from the point of view of the actor and their transformations, whether from the point of view of the establishment of new categories of relation and perception of art.

Keywords: Scene. Co-authoring. Friction.
1. Rita Gusmão: (ritag924@ gmail.com) Atriz diretora e produtora de espetáculos e eventos artísticos culturais. Desenvolve a palhaça Colibri desde 1996. Professora Adjunta da Universidade Federal de Minas Gerais, Escola de Belas Artes, Curso de Graduação em Teatro, no qual participa das modalidades de Bacharelado e de Licenciatura (desde 2002).

Tem trabalhos nas áreas de Teatro, Performance, Videoarte e videoinstalação. 
A atualidade pode ser vista como uma rede de poderes, que se estabelecem e se diluem com intensa velocidade. Dentre os poderes constituídos e voláteis, está o da produção artística e suas relações com a estética. No âmbito deste poder, dois agentes se relacionam de modo intenso e faiscante: o ator performático e o fruidor coautor. A constituição, tanto destes sujeitos quanto de sua relação, estão em andamento, e suas figuras servirão aqui como perspectiva para a compreensão de transformações nas Artes, que se mostram, por sua vez, também em plena conformação.

A sociedade na qual estão imersos estes agentes, não se organiza em torno de um discurso totalizante, ao contrário, o espaço de vida pós-moderna se baseia em polaridades. O horizonte é de discursos fragmentados que, em muitos casos, buscam entabular um caráter mítico para o coletivo. Este vínculo entre um ator performático e um fruidor coautor, emerge das habilidades de diferenciação e de agenciamento que fruidor e proponente da manifestação artística possuem nesta pós-modernidade. O agenciamento como um processo de crescimento exponencial das dimensões de percepção capaz de mudar, necessariamente, a natureza da percepção à medida que amplia as conexões (DELEUZE e GUATTARI, 1995, p.16). A diferenciação, a habilidade de apreender o real heterogêneo que se estabelece nas redes socioculturais, ou do próprio dinamismo das diferenciações entre os sujeitos destas redes.

Se pode observar o vínculo entre o ator performático com o fruidor coautor, como um processo de envolvimento com os objetos e ações artísticas, que é elaborado no íntimo dos sujeitos, individual e coletivo ao mesmo tempo, e que tem caráter de experiência sociocultural. É relativamente fácil observar que:

\footnotetext{
A desintegração dos discursos sociais afetou também [as artes da cena], e as identidades coletivas abriram espaço para os criadores em primeira pessoa. Como reação à dissolução dos tecidos sociais, o ator, procurando uma nova dimensão social, é impelido a mostrar-se como nome e sobrenome, a expressar-se em primeira pessoa, tentando reconstruir uma possibilidade do social, ou seja, do político, com base no pessoal, no próprio corpo. (CORNAGO, 2008, p. 25)
}

Esta desintegração sociocultural pode, também, ser considerada como típica dos anos 1990 e 2000, e tem mostrado um conjunto de relações e características de fricção que afetam os eixos da prática artística, e a cena ao vivo espelha em sua estrutura, por assim dizer, este contexto. Para destacar dispositivos que aqui são importantes, utilizaremos o conceito de biopolítico oferecido por Michel Foucault, por nos trazer pos- 
sibilidades de reflexão que se amalgamam com a proposta de friç̧ão e de coautoria.

A cena atual é um espaço no qual se aliam expectativas e desejos não somente em função do prazer, mas também como corolário de uma trajetória de composição da política do encontro, na qual o corpo é elemento crucial. Se compõe um agenciamento que é:

\begin{abstract}
um desafio estético, ético, político, subjetivo.(...) Estar à altura do que nos acontece é a única ética possível, estar à altura dos acontecimentos que se esteja em condições de propiciar, nos mais diversos campos, nas mais diversas escalas, moleculares e molares, recusando o niilismo biopolítico e suas formas cada vez mais insidiosas e capilares. A esses dispositivos vários, dos quais um certo teatro faz parte, eu chamaria de dispositivos biopolíticos, em que está em jogo uma potência de vida, uma biopotência. (PÁL PELBART, 2008, p. 37)
\end{abstract}

Biopolítico é o termo sugerido por Foucault para designar o exercício de poder que se configurou desde o final do século XIX e início do século XX, o qual criou intensidades e influenciou uma ideologia que vem atravessando o início do século XXI. Na biopolítica se expressam as três dimensões sobre as quais o capitalismo investiu para socializar e controlar o corpo: o biológico, o somático e a força de trabalho. "O corpo é uma realidade bio-política", diz Foucault, e completa: "o controle da sociedade sobre os indivíduos não se opera simplesmente pela consciência ou pela ideologia, mas começa no corpo, com o corpo" (FOUCAULT, 1986, p.80). Na dimensão biológica, as medicinas se afirmaram e passaram a controlar os corpos e as tensões políticas que a ocupação destes provoca no espaço coletivo. A medicalização da sociedade fez gerar o controle da água e do ar e a urbanização, numa busca de controle e governança das cidades, emblemas do progresso e da modernização. O somático foi sendo pouco a pouco fragmentado e ocupado por várias instâncias mais e menos autoritárias, com o deslocamento da atenção da governabilidade para as coisas em contraposição ao ser: o ar, a água, as decomposições, a salubridade (FOUCAULT, 1986, p.93). O corpo perde a centralidade da saúde para o controle das condições de aglomeração e do meio. A medicina manteve a pauta da formação de sistemas contra epidemias, garantida pelo Estado que, por sua vez, serviu de suporte a ela mas, também, às religiões, para tornar os cidadãos, principalmente os mais pobres, aptos ao trabalho e menos perigosos para os mais ricos.

A força de trabalho, no século XIX, se tornou alvo de uma "assistência controlada, de uma intervenção médica que é tanto uma maneira de ajudar os mais pobres a satisfazerem 
suas necessidades de saúde, sua pobreza não permitindo que o façam por si mesmos, quanto um controle pelo qual (...) os representantes (das classes ricas) asseguram (...) (sua) proteção" (FOUCAULT, 1986, p.95). "Vê-se, claramente, a transposição, na legislação médica, do grande problema político da burguesia nesta época: a que preço, em que condições e como assegurar sua segurança política” (Idem).

Desde os meados do século XVIII, no entanto, a arte veio se envolvendo nessa definição de territórios que estabeleceu a separação de classes mais e menos preparadas para o convívio e a ocupação dos lugares de desenvolvimento da cultura. A apreciação da manifestação artística, nesta conjuntura, se revelou uma categoria importante para a efetivação do julgamento sobre os seres, e a posse de objetos artísticos, uma garantia de hierarquização dos grupos sociais. Se desenvolveu e fortaleceu a noção de opinião pessoal:

essa invenção do século XVIII, enraíza-se na fé racionalista segundo a qual a faculdade de "julgar corretamente", como dizia Descartes, ou seja discernir o bem do mal, o verdadeiro do falso por um sentimento interno, espontâneo e imediato, é uma aptidão universal (como a faculdade de julgar esteticamente, segundo Kant) - (...). A ideia de "opinião pessoal" deve, talvez, em parte, sua evidência ao fato de que, constituída contra a pretensão da Igreja ao monopólio da produção de julgamentos, e inseparável da ideia de tolerância - ou seja, da contestação de toda autoridade em nome da convicção de que, nessas matérias, todas as opiniões, seja qual for seu produtor, são equivalentes - ela exprime, desde a origem, os interesses dos intelectuais, pequenos produtores independentes de opiniões, cujo papel se desenvolve paralelamente à constituição de um campo de produção especializado e de um mercado para os produtos culturais. (BOURDIEU, 2008, p. 372. Grifos do autor)

Com o contexto da opinião pessoal, deu-se o início do movimento de conversão do espectador em consumidor, embora este somente tenha sido assim entendido a partir da modernidade: aquele que escolhe entre os produtos oferecidos pelo artista ou pelo vendedor, sem que tenham sido produzidos para ele em particular. Entender o consumidor e o papel que esta posição social desempenhou na instauração da apreciação estética hierarquizante, auxilia a desvendar a fricção entre política e arte neste movimento. Para Anne Cauquelin,

Para que os mediadores-intermediários da cadeia de consumo de arte- como de qualquer outro produto - sejam eficazes, é necessário isolar o produtor, o artista, como se ele não tivesse consciência do destino de sua produção. É o mediador que tem essa consciência, que a desenvolve e a sustenta. Porque é ele quem tem o conhecimento do consumidor virtual. Quem é, então, esse consumidor? 
Em primeiro lugar, o colecionador, geralmente qualificado de "grande". Burguês ou aristocrata esclarecido, amante de coisas belas e possuidor de meios para satisfazer seus gostos.(...). Agente ativo do mercado, assegura também a troca com outros colecionadores, fazendo transitar as obras de um país para outro. (...). Em seguida vem os diletantes, informados, que compram para seu prazer e com o pensamento primeiro de fazer um bom negócio. (...). Curiosidade, gosto pelo risco, prazer de ter olho clínico, sentimento de participar de um mundo à parte, justamente o dos colecionadores, tudo são atrativos para o turista-apreciador. (...). Finalmente, o público que consome pelo olhar, que fica diante da vitrine, exercendo um papel passivo, mas importante, de puro espectador; por meio de sua massa móvel, sustenta a totalidade do mecanismo. A ele compete o reconhecimento, a opinião firmada. É ele quem transporta o boato. É a ele que compete formar e transformar a imagem do artista e a da arte. Sem ele não há a vanguarda, dado que a ela faltaria o objetivo de uma provocação renovada. (CAUQUELIN, 2005, p. 49/50/51)

O desenvolvimento industrial se relacionou com a arte estimulando, produzindo e propagando fricções. O fruidor foi estimulado a auto-referenciar-se, e assim também o artista proponente, de modo que se estabelecessem frestas nas quais cada indivíduo explicasse e completasse por conta própria as motivações internas de cada manifestação. A obra incompleta, inexaurivel, indefinível tornou-se mais atraente e mais expressiva, e as reviravoltas, parte de sua estrutura. A arte moderna nasce de um compromisso com uma época de incertezas para o ser humano e, depois, a arte pós-moderna encara sua existência como uma luta e uma competição, que traduz para o ser o movimento e a mudança, a experiência do mundo, que se converte cada vez mais em experiência de temporalidade. "A temporalidade é uma apreensão perceptiva, que possibilita distinguir o agora e as retenções, na qual o presente constrói o tempo como unidade da percepção" (CAUQUELIN, 2008, p.94).

E assim, no pós-moderno a percepção estética se torna uma dimensão da relação social com o mundo e com o outro. E se torna também a "expressão distintiva de uma posição privilegiada no espaço social" (BOURDIEU, 2008, p. 56). O valor distintivo determina-se pelas condições de acesso aos bens culturais. A elaboração dos gostos, "preferências manifestadas" (Idem) são a assunção prática de diferenças que se afirmam pela recusa e oposição a outros gostos; "os gostos são, antes de tudo, aversão, feita de horror ou de intolerância visceral aos outros gostos, aos gostos dos outros" (Ibidem. Grifo do autor). Noutras palavras, o fruidor aprendeu a valorizar seu gosto, mas na modernidade este esteve baseado no senso comum, e na sociedade pós-moderna se traduz numa "escolha do destino, embora forçada, produzida por condições de existência que, 
ao excluir qualquer outra possibilidade, deixam como única escolha o gosto pelo necessário" (BOURDIEU, 2008, p.169).

Pensado sob estes princípios, pode-se dizer que o gosto se manteve como operador prático das relações com a manifestação artísticas da modernidade, que teve como princípio pragmático a unidade, até a pós-modernidade, a partir dos anos 1960 para a maioria dos estudiosos, cuja circunstância artística é "dos valores propriamente plásticos [que] tendem a ser absorvidos na plasticidade das estruturas perceptivas e situacionais" (PEDROSA apud TEIXEIRA COELHO, 1990, p. 64/5).

Enquanto o gosto ocasiona sinais distintivos, sinais de vínculos sócio-afetivos, mesmo que sejam estabelecidos por oposições de individualidades, auxilia a sustentar a biopolítica, porque ele faz com que as diferenças inscritas inicialmente numa ordem física de corpos se tornem um acesso à ordem simbólica. O gosto se fragmenta em fricções simbólicas, que se opõem à percepção estética dominante. Este gosto está baseado numa espécie de "adesão primitiva, de crença elementar que une cada agente a seu estilo de vida: a redução materialista das preferências às suas condições econômicas e sociais de produção, assim como às funções sociais desempenhadas pelas práticas, na aparência, mais desinteressadas" (BOURDIEU, Op. Cit., p. 291).

O gosto se forma na acessibilidade imediata a produtos oferecidos, entendida aqui como as políticas de acesso desenvolvidas pelos projetos de distribuição de eventos de governos, de Estados e empresariais, e que compõem a estratégia de estímulo ao reconhecimento e a reverência à cultura e à arte, montada para dar suporte biopolítico à descarga de satisfação do fruidor. Numa crítica desta estimulação podemos pensar na vulgarização do símile, das imitações oferecidas ao consumidor com a perspectiva de que "é mais barato e faz o mesmo efeito", substituindo a habilidade real de escolha por um processo inconsistente de posse. O mercado constrói um gosto para que o consumidor se considere satisfeito com os produtos aos quais lhe é facultado o acesso, gosto que não o realiza necessariamente como fruidor e que oferece referentes que são habilitados para confundir a percepção estética com o efeito de posse.

Por outro lado,

O mercado de arte, (...) é afetado regularmente por seu próprio movimento (...). A retração brutal de compradores [desde a crise econômica dos anos 1990], os efeitos da recessão econômica, a crise de confiança alimentada por episódios [midiáticos] infelizes, etc., tudo isso concorreu para o estouro de uma bolha especulativa. (...). No mercado de arte, as expectativas de ganho cresceram de 
tal maneira [nos últimos vinte ou trinta anos] que se desencadeou uma espiral especulativa, seguida de vendas maciças e desordenadas. (BENHAMOU, 2007, p. 82/3)

Neste contexto de mudanças paradigmáticas no capitalismo industrial, o artista assume uma nova tarefa social de intervenção política e educativa, com características ainda de fricção, fortalecendo um processo de afirmação filosófica da própria profissão. Num primeiro momento, essa afirmação se pautou por hierarquizar sua relação com os fruidores-consumidores de objetos artísticos, mantendo-os como capazes e incapazes, e ainda se pode localizar relações desta natureza nos dias de hoje. A arte ainda se organiza no entre da expressão da individualidade, a multiplicidade sem unidade possível e um processo com vistas a desenvolver, ou aperfeiçoar, uma apreensão estetizada do mundo. Mas, num segundo momento, o conhecimento empírico vem sendo valorizado em relação à investigação científica, as manifestações buscam um campo conceitual novo, e o artista busca um discurso capaz de aproxima-lo de um fruidor participante ativo.

A presença daquele que ainda se sente e se vê como espectador, é solicitada para a realização conjunta da enunciação das manifestações. Há um projeto de discurso que "descentra o sujeito (de um sentido, de uma estrutura) e constrói-se como a operação de sua pulverização numa infinidade diferenciada" (KRISTEVA, 2005, p. 18. Marca da autora). Assiste-se, a partir destas circunstâncias socioculturais e da instituição de atos significantes no campo do prazer estético, à individualização da clientela da arte (CAUQUELIN, 2005, cap. I). O que se quer mostrar com estas reflexões é que as unidades de significação expressas pelas noções de "gosto" e de "mercado" são friccionadas por uma tentativa do artista proponente de superar a compreensão da manifestação como mercadoria.

No caso da cena ao vivo, são as teatralidades plurais que suportam esta enunciação, e que vem possibilitando uma inter-relação entre o significado e o gosto e um outro formato de apreensão da manifestação artística. A formulação da fricção entre ator e fruidor está intimamente relacionada à autonomização da manifestação em relação ao limites do gosto e do mercado. O ator é elemento chave para esta autonomização, e o fruidor coautor será seu parceiro afetivo.

Como características do ator performático para este movimento da cena ao vivo pode-se relacionar: "sensorialidade alargada, circulação ininterrupta de fluxos, sinergia coletiva, pluralidade afetiva e subjetividade coletiva (PÁL PELBART, 2008, p. 35/6). De início, é importante deixar de lado 
(...) a hipótese de que toda a encenação está organizada segundo operaç̃̃es de vetorização e que existem sinais globais, sinais de gestalt, quer dizer, vetores totalizadores que estruturam um conjunto da encenação e aos quais estarão subordinados todos os significantes individuais que os espectadores poderão reconhecer. (PAVIS, 2008, p. 215)

São as oportunidades de confronto direto com o outro, necessidade que cresce na sociedade global quase com a mesma rapidez que as tecnologias relacionais, que se transformaram em formas de intercâmbio, com caráter econômico e de produto de consumo. Aqui existe uma ruptura com o pacto de recepção, como entendida na teatralidade vetorizada para a totalização, e emerge em seu lugar

uma sequência de unidades que Garcia-Martinez nomeou quadros rítmicos, ou seja, "traço mental do ritmo dos primeiros instantes que se torna o ponto de referencia do desenvolvimento rítmico ulterior", o que definimos aqui como as vetorizações do espetáculo e que constrói o sentido e o ritmo como uma sequência de quadros ou seguimentos orientados. (PAVIS, 2008, p. 214/5)

Interessam agora as modificações tônico-posturais do fruidor, busca-se a reabilitação de sua avidez, de seus sentidos muitas vezes esterilizados ou anestesiados pela vivência cotidiana com o mundo maquínico, a conscientização da biopolítica e o posicionamento diante dela. A tarefa da manifestação artística é a de sentir e fazer sentir a atmosfera do encontro, aquilo que o torna único e não reproduzível.

A teatralidade recorre a um dos seus elementos por definição, a presença do espectador, para transformar em tema de discussão algo que em outro momento pode ter parecido natural, a constituição de um grupo social em torno da atuação. Em outras palavras, diríamos que o ato [cênico] se torna uma ocasião para o encontro com o outro, porém um tipo de encontro que adquire algumas características particulares. Não consiste, como explica Toni Negri, em formar novos grupos, novas estruturas estáveis, ligados, por sua vez, a discursos ideológicos ou econômicos, mas sim em devir-grupo, recuperando a terminologia de Gilles Deluze, em devir-social, em tornar o social um acontecimento aqui e agora (...).Diante da ideia de grupo se estende o imaginário da rede, uma estrutura que viva em contínuo fazer-se e desfazer-se à medida que ocorrem os cruzamentos. (CORNAGO, 2008, p. 25)

Para além da relação entre o exterior à cena e seu mecanismo de teatralização, revigora-se a vinculação entre aquele(a) que ocupa a cena, e aquele(a) ao qual ela se dirige, e, nessa relação se projeta um compromisso ético e estético do ator que é político. Essa relação de proximidade se dá no artista proponente diante 
de sua própria manifestação, continua na relação entre os outros proponentes envolvidos, outros artistas que compõem a cena, e passa para a vinculação entre a manifestação e o fruidor, projetando-se para o social além jogo cênico, além do espaço-tempo ocupado por ele. $\mathrm{O}$ encontro busca expressar uma atitude que remete a uma tomada de posição ética. Essa tomada de posição é uma operação estética.

$\mathrm{O}$ ator se faz performático: explora uma dialógica assentada na relação de complementaridade com o fruidor e uma mentalidade processual de construção do trabalho de atuar, ampliadora da sua expressividade artística e do momento de presentação, tornando-o poroso. A atuação performática referencia uma troca do esquema de vetorização totalitária a partir de um texto espetacular, pré-concebido e fechado, para a construção de enunciação dramatúrgica conjunta, para uma forma de discurso sensorial, em que a parataxe e a estrutura de jogo são elementos essenciais da manifestação. Ao salientar-se que esta atuação se organiza pela transitoriedade de estilos, reprodutibilidade de atmosferas, pela simultaneidade de estimulações e a reelaboração contínua do diálogo direto como o fruidor, pode-se conceber o grau de fricção que esta atuação provoca. Este ator cria endereçamentos sensoriais que se ligam à sensibilidade estética pós-moderna, sejam eles, a polissensorialidade, a multiplicidade, o recurso ao mitológico, a não-submissão ao racional, a recorrência à presença do fruidor como catalisador do evento e uma certa indiferença diante da necessidade do novo, no sentido de que cada manifestação vive o espaço e o tempo específicos onde se coloca.

Do outro lado, o fruidor coautor opera nas manifestações artísticas como ser-artista potencial, que tende a recorrer ao tempo como suporte capaz de estabelecer o trabalho da percepção. Bourriaud aponta isso quando diz que "já não se pode considerar a obra contemporânea como um espaço a ser percorrido. Agora ela se apresenta como uma duração a ser experimentada, como uma abertura para a discussão ilimitada" (BOURRIAUD, 2009, p. 20/1). Contudo, pode-se observar que esta narrativa não se caracteriza pelo sequenciamento e se mostra como uma tentativa de fazer estar junto, "de manter juntos momentos de subjetividade ligados a experiências singulares" (Idem, p. 27). O sentido ressurge como o aglutinante que dispensa a narrativa regular e elabora uma simetria de ações e percepções no tempo e no espaço, que serve de meio para uma fruição que é uma relação com a carne do mundo, uma fricção operativa sobre relações inter-humanas.

A obra expressa uma atitude cênica que remete a uma tomada de posição ética. Torna-se, então, visível um determinado tipo de 
relação do criador e seu trabalho, do ator e o público, do eu diante do tu. Esse tipo de comunicação próxima, em primeira pessoa, constrói um eu pessoal e físico, atravessado por uma necessidade social, pela busca do tu, que define o ser-social. Perante a hermenêutica de Heidegger, Lévinas defende o eu-para-o-outro antes do eu-com-o-outro. Esta ontologia ética leva a uma abertura da cena para o público. (CORNAGO, 2008, p.26)

O sistema cultural pós-moderno atual não apresenta garantias para os indivíduos que possibilitem uma completude ou uma estrutura definida de relações e ações. Na atualidade a manifestação artística, e a cena ao vivo, ativam uma condição de potência corporal e de experiência coletiva a ser explorada por atores proponentes e fruidores participantes, tornando visível o jogo no qual ambos realizam suas capacidades de afetar e serem afetados. Ao mesmo tempo, fá-los pertencerem a um grupo onde suas individualidades não se diluem totalmente, gera um pertencimento que não apaga cada presença. Esse jogo é, principalmente, o de pensar como atores, de atender a um convite de integrar-se a um espaço-tempo lúdico e experimental, que expõe e que alimenta a sensibilidade. Esta cena emerge como parâmetro de um funcionamento grupal, "a partir de uma vontade prévia, que define uma capacidade, transformada por sua vez em um novo modo de enfrentar o ato grupal da atuação" (CORNAGO, 2008, p. 29). Um projeto estético de natureza diferenciada e, pode-se dizer, que institui uma esfera artística específica.

O modo contemporâneo de produção em arte parece organizar-se como uma atitude de estabelecer fluxos comunicativos entre comunidades auto-organizadas, o que significaria, de um ponto de vista da percepção estética, a emersão de uma sensibilidade própria à criação, contínua e constante, de modelos simbólicos válidos para si mesmos, que se posiciona em paralelo ao exercício de controle da perspectiva teórica e instituinte de escolas, teorias e mídias. Esta atitude implica uma perda, aparentemente consciente, do controle do artista sobre sua obra, pois ao fruidor atribui o papel de agente de manipulação do sistema em que aquela se expressa. E, ainda, a continuidade, ou permanência, da obra, depende da intercomunicação entre os participantes, o que só se faz possível a partir do desenvolvimento de uma arquitetura de contatos amplamente flexível, que expande a intervenção e pode até criar, com sua volatilidade, novas comunidades a cada novo participante. A manifestação artística passa a ser percebida não mais como objeto visível e estocável mas, sim, como poética ambiental e polissensorial, que fricciona os papéis atribuídos ao criador, ao tempo e ao participante, promovendo uma interação criativa entre todos. Superando a forma em favor do encontro. 
BENHAMOU, Françoise. A Economia da Cultura. Tradução de Geraldo Gerson de Souza. Cotia/SP: Ateliê Editorial, 2007.

BOURDIEU, Pierre. A Distinção: crítica social do julgamento. Tradução: Daniela Kern; Guilherme J.F. Teixeira. São Paulo: Edusp; Porto Alegre/RS: Zouk, 2008.

BORRIAUD, Nicolas. Estética Relacional. Tradução: Denise Bottmann. São Paulo: Martins, 2009. (Coleção Todas as Artes) CAUQUELIN, Anne. Arte Contemporânea: uma introdução. Tradução: Rejane Janowitzer. São Paulo: Martins, 2005. (Coleção Toda as Artes)

Frequentar os Incorporais. Contribuição a uma Teoria da Artes Contemporânea. Tradução Marcos Marcionilo. São Paulo: Martins, 2008. (Coleção Todas as Artes) CORNAGO, Oscar. Teatralidade e Ética. In: próximo ato: questões da teatralidade contemporânea. Org. Fátima Saadi e Silvana Garcia. São Paulo: Itaú Cultural, 2008.

DELEUZE, Gilles e GUATTARI, Felix. MIL PLATÔS Capitalismo e Esquizofrenia. Vol. 1. Tradução de Aurélio Guerra Neto e Célia Pinto Costa. RJ: Ed. 34. 1995. 94 p. (Coleção TRANS).

FOUCAULT, Michel. Microfísica do Poder. Tradução e organização Roberto Machado. Rio de Janeiro: Edições Graal, 1986.

GADAMER, Hans-Georg. Estética y hermenêutica. Traducción de Antonio Gómez Ramos. Madrid: Editorial Tecnos (Grupo Anaya S.A.), 2001. $2^{\text {a }}$ edición.

KRISTEVA, Julia. Introdução à Semanálise. Tradução: Lúcia Helena França Ferraz. São Paulo: Perspectiva, 2005. $2^{\mathrm{a}}$ edição. (Debates - 84)

PÁL PELBART, Peter. "Elementos para uma cartografia da grupalidade”, In: próximo ato: questões da teatralidade contemporânea". Org. Fátima Saadi e Silvana Garcia. São Paulo: Itaú Cultural, 2008.

PAVIS, Patrice. A análise dos espetáculos: teatro, mímica, dança, dança-teatro, cinema. Tradução Sérgio Sálvia Coelho. 2.ed. São Paulo: Perspectiva, 2008. (Estudos; 196)

TEIXEIRA COELHO NETO, José. Moderno Pós-moderno. SP: L \&PM, 1990. $2^{\mathrm{a}}$ Edição. 